\title{
How confident are pharmacists in providing pharmaceutical care on anticoagulants? A cross-sectional, self-administered questionnaire study in Borneo, Malaysia
}

\author{
Sze Ling Tan ${ }^{1 *}\left(\mathbb{0}\right.$, Zai Yang Yong ${ }^{2}$, Jerry Ee Siung Liew ${ }^{3}$, Hadzliana Zainal $^{4}$ and Sania Siddiqui ${ }^{4}$
}

\begin{abstract}
Background: Anticoagulants are the cornerstone therapy for the management of venous thromboembolism (VTE) and atrial fibrillation (AF). Pharmacists should be confident and equipped with the skill and updated knowledge in managing anticoagulation therapy.

Objective: To explore self-reported confidence level of pharmacists, perceived reasons influencing their confidence and socio-demographic associated with high confidence level in the area of anticoagulation.

Methods: A cross-sectional, self-administered questionnaire survey was carried out among fully registered pharmacists who work in selected government hospitals and clinics in Borneo, Malaysia, from January 2019 to February 2020.

Results: Overall, responses from 542 fully registered pharmacists were obtained. Proportion of respondents who claimed confident in providing necessary information to patient receiving warfarin ( $n=479,88.3 \%)$ was significantly higher $(p<0.001)$ compared to low molecular weight heparins $(n=317,58.5 \%)$ and direct oral anticoagulants ( $n=211,38.9 \%)$. Respondents' perceived reasons that may influence their confidence level include experience in dealing with anticoagulants' cases $(n=469,86.5 \%)$, knowledge on anticoagulants ( $n=394,72.7 \%)$ and knowledge on diseases needing anticoagulation therapy $(n=311,57.4 \%)$. Practising as ward pharmacist and "always" dealing with anticoagulants during their practice were the socio-demographic that significantly associated with high confidence level of pharmacist in providing pharmaceutical care on all types of anticoagulants $(p<0.05)$.
\end{abstract}

Conclusion: Pharmacists were found more confident in providing pharmaceutical care on warfarin compared to low molecular weight heparins and direct oral anticoagulants. Continuous educational and training programmes on the use of anticoagulants should be carried out to enhance pharmacists' confidence in supporting patients' care.

Keywords: Anticoagulants, Pharmaceutical care, Confidence, Borneo Malaysia

Editorial responsibility: Zaheer Babar, University of Huddersfield, UK

*Correspondence: szeling@moh.gov.my

1 Pharmacy Department, Hospital Queen Elizabeth II, Kota Kinabalu, Sabah, Malaysia

Full list of author information is available at the end of the article

\section{Introduction}

Anticoagulants are the cornerstone therapy for the management of venous thromboembolism (VTE) and atrial fibrillation (AF) [1]. VTE is one of the leading cause of mortality worldwide and estimated to be the third most common vascular disease after myocardial infarction and stroke [2]. The actual incidence of VTE in Malaysia remains unknown, however literatures showed an original author(s) and the source, provide a link to the Creative Commons licence, and indicate if changes were made. The images or other third party material in this article are included in the article's Creative Commons licence, unless indicated otherwise in a credit line to the material. If material is not included in the article's Creative Commons licence and your intended use is not permitted by statutory regulation or exceeds the permitted use, you will need to obtain permission directly from the copyright holder. To view a copy of this licence, visit http://creativecommons.org/licenses/by/4.0/. The Creative Commons Public Domain Dedication waiver (http://creativeco mmons.org/publicdomain/zero/1.0/) applies to the data made available in this article, unless otherwise stated in a credit line to the data. 
increase trend in the incidence rates in both Western and Asian countries $[3,4]$. On the other hand, AF is the commonest sustained cardiac arrhythmia that affects $1 \%$ of the global population, and approximately $0.54 \%$ in Malaysia population [5]. It is known that AF increases the risk of stroke and based on $\mathrm{CHA}_{2} \mathrm{DS}_{2}$-VASc (congestive heart failure, hypertension, age $\geq 75$ years, diabetes mellitus, stroke or transient ischaemic attack, vascular disease, age 65 to 74 years, sex category) score, patient should receive oral anticoagulant if one does not fall into the "low risk" category [6]. Various guidelines have recommended the use of anticoagulants such as vitamin $\mathrm{K}$ antagonists (VKAs) or direct oral anticoagulants (DOACs), in some circumstances, low molecular weight heparins (LMWHs), as part of the pharmacotherapy in management of AF and VTE used to reduce thromboembolism complications, risk of stroke and mortality [7-13]. Warfarin is the oldest and most widely used vitamin $\mathrm{K}$ antagonist [14]. Warfarin has a narrow therapeutic index which requires frequent International Normalised Ratio (INR) monitoring and known to have multiple interactions with drugs, food and supplements [15]. The emergence of DOACs since last decade has gained popularity as these newer agents have demonstrated similar efficacy but a better safety profile compared to warfarin in management of AF [16-20] and VTE [21, 22]. Due to the advantages of DOACs such as minimal anticoagulation monitoring needed and less documented drugs/ supplements-related interactions, the usage of DOACs has steadily increased. The Malaysian Statistics on Medicines (MSOM) has shown that the usage of DOACs such as dabigatran and rivaroxaban is increasing steadily from year 2011 to 2014 in both private and government sector [23]. In Malaysia's government hospitals and clinics, pharmacist-initiated medication counselling session are given to patients who are newly started on warfarin, LMWHs (enoxaparin) and DOACs (dabigatran, rivaroxaban, apixaban) [24, 25]. Literatures have proven that the involvement of pharmacists in anticoagulation management has positive impact in improving safety and efficacy outcomes in patients taking warfarin [26] or receiving DOACs [27]. To date, only two published questionnairebased studies have assessed the confidence level among pharmacists in dealing with anticoagulants. The first multinational survey was conducted by Papastergiou et al. [28], involving 4212 pharmacists from 18 countries (not including Malaysia). This study showed that pharmacists' confidence level was significantly lower $(p<0.001)$ when advising patients on DOACs compared to VKA. Another study was carried out by Hamedi et al. [29] aimed to assess the community pharmacists' current practice, knowledge and confidence in supporting patient's adherence on oral anticoagulants for stroke prevention in atrial fibrillation in London via online survey where 257 community pharmacists responded. Results documented that pharmacists were less confident in their knowledge, skills and access to resources for DOACs than for VKA $(p<0.005)$. The unfamiliarity and minimal exposure to DOAC is reflected in their knowledge and confidence. Both studies did not assess the confidence level on advising LMWHs even though LMWHs are commonly used as parenteral anticoagulant especially in in-patient care.

Up to the present, warfarin, LMWHs such as enoxaparin, and DOACs such as dabigatran, rivaroxaban, apixaban are approved by Ministry of Health medicines formulary (MOHMF) Malaysia [30] to be used as part of the management in AF and VTE. Pharmacists, whether involved directly or indirectly with patient care, should be confident and well equipped with the skills and updated knowledge in managing anticoagulation therapy. However, there is lack of assessment on the confidence level of pharmacists in providing pharmaceutical care on anticoagulants to these patients. Thus, this study aimed to assess the self-reported confidence level of pharmacists in Borneo, Malaysia, in terms of providing necessary information on 3 types of anticoagulants (warfarin, LMWHs and DOACs) and discussing various aspects of anticoagulation therapy with patients. This study also described the socio-demographic associated with high confidence level, respondents' perceived reasons that influencing their confidence as well as education needs in the area of anticoagulation therapy in order to identify the potential methods to fill in the gap.

\section{Methods}

\section{Study methods}

This was a cross-sectional, self-administered questionnaire study which was carried out in Pharmacy Department of government hospitals and clinics in Borneo (Sabah and Sarawak) from January 2019 until February 2020. Sample size of 526 respondents is required with expected $53 \%$ of pharmacist claim confident in providing pharmaceutical care on DOACs [28], also with precision of $2.5 \%$ and $95 \%$ confidence interval (refer Additional file 1: Appendix for details) [31]. In order to ensure there was adequate representation from both hospitals and clinics in Borneo, all facilities in Sabah and Sarawak were being stratified into six strata, respectively: hospital (main zone), clinic (main zone), hospital (district 1), clinic (district 1), hospital (district 2), clinic (district 2). Then, simple random sampling was employed to select facilities in each strata to meet the responses needed. All the fully registered pharmacists (FRPs) working in the selected facilities were approached via either email or by investigators; upon consent, they were required to fill up the questionnaire form and return to investigators. This 
study was approved by the Medical Research and Ethics Committee, Malaysia, with the identification code of NMRR-18-2821-44278 (IIR) for Sabah and NMRR-193270-51648 for Sarawak.

\section{Instrument}

The questionnaire used in this study comprises of five domains: (i) socio-demographic; (ii) self-report confidence level in providing necessary information on 3 types of anticoagulants (warfarin, LMWHs and DOACs) and discussing various aspects in anticoagulation therapy using 4-point Likert scale ranging from not confident at all to very confident, (iii) perceived reason(s) influencing confidence level; (iv) ways used by pharmacists to obtain latest information on anticoagulants; (v) education needed in the area of anticoagulation therapy. Domain (ii) and (v) of the questionnaire were adapted from the validated questionnaire (refer Additional file 1: Appendix for psychometric properties) used in multinational survey by Papastergiou et al. [28] after obtaining authors' consent. Content validation using Delphi technique and pre-test were carried out among university lecturers and hospital pharmacists to ascertain the comprehensive and user-friendliness of questionnaire.

\section{Data analysis}

Analysis was conducted using STATA/SE 12.0 (StataCorp, College Station, TX, USA). Continuous variables were presented in mean (standard deviation, SD) or median (interquartile range, IQR) depending on the normality of data distribution. Categorical data were presented as frequency and percentage. Before conducting univariate analysis, data were explored to check for any errors and incorrect data entry. Categorical variables were merged if there were cells with zero values. Proportion of confidence across 3 types of anticoagulants were analysed using Chi-square, then Bonferroni correction was done for multiple comparisons. For this, a $p<0.017$ (3 comparisons) was considered as statistically significant. Subsequently, logistic regression analysis was adopted.

We aimed to determine the factors associated with pharmacist's confidence level (confident vs not confident) in advising anticoagulants (warfarin). The first step in fitting the model was to conduct univariable logistic regression. The relationship between each socio-demographic and dependent variable (pharmacist's confidence level in advising warfarin) was evaluated. Variables that were found to be statistically significant $(p<0.25)$ and additional variables that might plausibly affect the dependent variable were considered as candidate variables in multiple logistic regression. In order to identify the factors that would provide the most parsimonious model within the constraint of current collected data, best subsets selection using Furnival-Wilson leaps-and-bounds algorithm [32] was employed. This algorithm organised all subsets of factors in tree structures and evaluated them by skipping (or "leaping") over a subset that was not optimal. The subsets of factors created were all possible combinations of socio-demographic variables (age, working experience as pharmacist (months), place of practice, zone of practice, department of practice, warfarin MTAC involvement and frequency of warfarin used in practice). The best subset was determined based on smallest Bayesian information criterion (BIC) and Akaike's (1974) information criterion (AIC) value as well as the largest log likelihood. After executing the algorithm, a total of 7 subsets of factors were generated. The subset that consisted of department of practice $\left(X_{1}\right)$ and frequency of warfarin used in practice $\left(X_{2}\right)$ were found to have the smallest BIC (364.3553) and AIC value (351.4751). This subset provided the best possible explanation of the dependent variable (pharmacist's confidence level in advising warfarin). Hence, a preliminary main effect model was obtained.

Subsequently, the adequacy of the preliminary main effect model was studied. This included checking for interaction effect, multicollinearity and analysis of residuals. The presence of an interaction effect was assessed by forming a new variable that was the product of $X_{1} \times X_{2}$ and including this product term in the regression, along with the original predictor variables. No interaction effect was detected as the product of $X_{1} \times X_{2}$ was statistically not significant $(p>0.05)$. For multicollinearity assessment, variance inflation factor (VIF) for each factor was calculated and VIF of more than 5 was deemed to represent critical level of multicollinearity. Moreover, high correlation among predictors may also be presented if multicollinearity was an issue. A large inflated standard error, usually more than 5 would be observed. From our analysis, VIF for both factors were less than 5 (VIF $=1$, respectively, for each variable) and their standard errors were small (department of practice, OR 5.56, $\mathrm{SE}=3.39$; frequency of warfarin used in practice, $\mathrm{OR}$ 4.71, $\mathrm{SE}=1.43)$. Therefore, no multicollinearity was detected. As for the analysis of residuals, the main aim was to detect potential outliers, especially influential outliers. The outliers are deemed influential if extreme values can unduly influence the results of the analysis and lead to serious ramifications on the validity of the inferences. Potential outliers were detected from standardised residuals. Cook's distance was calculated to determine whether the outliers were influential enough. An observation was considered as an outlier if it had a standardised residuals of larger than 2 or smaller than -2 and the outliers were influential if Cook's distance was greater than 1. Residual analysis showed that an observation (Case ID: 
5) fulfilled criteria of being an influential outlier. Hence sensitivity analysis was conducted. A model that included this observation was compared with a model without this observation and it was noted that a significant improvement in parameter estimates and reduction in standard error were notable. Thus, this observation was removed from the final model $(n=541)$.

For model fit assessment, Pearson $\chi^{2}$ goodness-of-fit (GOF) test and Hosmer-Lemeshow test were carried out. Test results obtained showed a large $p$-value of more than 0.05 for both tests. This indicated that the data fit the logistic regression model well.

Finally, the performance of the model was evaluated by examining the ability to classify and discriminate between the two levels of response variable. The classification tools utilised were classification table and area under the receiver operating curve (ROC curve). A cut-off value of $>70 \%$ indicates excellent discriminating power between the two levels of the response variable. Analysis result showed that the overall correctly classified percentage and area under the ROC curve were $88.54 \%$ and $71.09 \%$, respectively. Hence, the final model was obtained. The parameter estimates from the model were interpreted as odds ratio (OR).

Similar ways in conducting logistic regression were repeated to determine socio-demographics that may be associated with pharmacist's confidence level in advising LMWHs and DOACs. All assumptions of logistic regression (adequacy of the logistic regression model, model fit assessment and model discrimination ability) were checked. Logistic regression assumption test results were presented concomitantly with each model plot (Fig. 2). All probability values were two-sided. A $p$-value of less than 0.05 was considered statistically significant.

\section{Results}

\section{Characteristics of respondents}

A total of 542 FRPs (260 from Sabah and 282 from Sarawak) responded to the questionnaire. Table 1 summarises the characteristics of all respondents. Among 542 respondents, majority were female $(n=428,79.0 \%)$ with median age of 30 years old and median month of working as pharmacist of 61.5 months. Warfarin remains the most common anticoagulant encountered by pharmacists during their practice with $58.3 \%(n=316)$ respondents claimed they "always" deal with it during their practice.

\section{Confidence level of respondents}

The distribution of respondents' confidence level according to the type of anticoagulants is shown in Table 2. It was found that there were significant differences in the proportion of confidence across the 3 types of anticoagulants $\left(X^{2}=285.1 ; d f=2, p<0.001\right)$. Bonferroni post hoc
Table 1 Socio-demographics of respondents

\begin{tabular}{|c|c|}
\hline Characteristics & $n(\%)$ \\
\hline \multicolumn{2}{|l|}{ Gender } \\
\hline Female & $428(79.0)$ \\
\hline Male & $114(21.0)$ \\
\hline Age (year) & $30(4)^{\mathrm{a}}$ \\
\hline Working experience as pharmacist (month) & $61.5(62)^{\mathrm{a}}$ \\
\hline \multicolumn{2}{|l|}{ Zone of practice } \\
\hline Main town & $251(46.3)$ \\
\hline District 1 & $180(33.2)$ \\
\hline District 2 & $111(20.5)$ \\
\hline \multicolumn{2}{|l|}{ Place of practice } \\
\hline Hospital & $395(72.9)$ \\
\hline Clinic & $147(27.1)$ \\
\hline \multicolumn{2}{|l|}{ Place of practice according to zone } \\
\hline Hospital (Main Zone) & $189(34.9)$ \\
\hline Hospital (District 1) & $126(23.2)$ \\
\hline Hospital (District 2) & $80(14.8)$ \\
\hline Clinic (Main Zone) & $62(11.4)$ \\
\hline Clinic (District 1) & $54(10.0)$ \\
\hline Clinic (District 2) & $31(5.7)$ \\
\hline \multicolumn{2}{|l|}{ Department of practice } \\
\hline Outpatient & $269(49.6)$ \\
\hline Ward & $95(17.5)$ \\
\hline Inpatient & $74(13.7)$ \\
\hline Administrative & $11(2.0)$ \\
\hline Others & $93(17.2)$ \\
\hline \multicolumn{2}{|l|}{ Warfarin MTAC involvement } \\
\hline Never & $395(72.9)$ \\
\hline Previously & $76(14.0)$ \\
\hline Currently & $71(13.1)$ \\
\hline \multicolumn{2}{|l|}{ Anticoagulant deal by respondent in practice } \\
\hline \multicolumn{2}{|l|}{ Warfarin } \\
\hline Never & $25(4.6)$ \\
\hline Rarely & $58(10.7)$ \\
\hline Sometimes & $143(26.4)$ \\
\hline Always & $316(58.3)$ \\
\hline \multicolumn{2}{|l|}{ LMWHs } \\
\hline Never & $62(11.4)$ \\
\hline Rarely & $167(30.8)$ \\
\hline Sometimes & $192(35.4)$ \\
\hline Always & $121(22.3)$ \\
\hline \multicolumn{2}{|l|}{ DOACs } \\
\hline Never & $84(15.5)$ \\
\hline Rarely & $224(41.3)$ \\
\hline Sometimes & $184(33.9)$ \\
\hline Always & $50(9.2)$ \\
\hline
\end{tabular}

DOACs direct oral anticoagulants, LMWHs low molecular weight heparins, MTAC medication therapy adherence clinic

a Data skewed to the right, $p<0.05$ in Kolmogorov-Smirnov statistic with a Lilliefors significant level 
Table 2 Distribution of pharmacists' confidence level according to type of anticoagulants

\begin{tabular}{lllll}
\hline $\begin{array}{l}\text { Type of } \\
\text { anticoagulant }\end{array}$ & $\begin{array}{l}\text { Confident } \\
\boldsymbol{n}(\%)\end{array}$ & $\begin{array}{l}\text { Not confident } \\
\boldsymbol{n}(\%)\end{array}$ & $x^{\mathbf{2}}$ & $\boldsymbol{p}$ value* \\
\hline Warfarin & $479(88.3)$ & $63(11.7)$ & $285.1^{\mathrm{a}}$ & $<0.001$ \\
LMWHs & $317(58.5)$ & $225(41.5)$ & & \\
DOACs & $211(38.9)$ & $331(61.1)$ & & \\
\hline
\end{tabular}

DOACs direct oral anticoagulants, $L M W H$ s low molecular weight heparins

${ }^{\text {a }}$ Chi-square test for independence; 0 cells ( $0 \%$ ) have expected count less than 5

${ }^{\text {a }}$ The minimum expected count is 206.33

tests has shown that the proportion of respondent who reported confident in providing necessary information to patient receiving warfarin was significantly higher than LMWHs $\left(X^{2}=124.12 ; d f=1 ; p<0.001\right)$ and DOACs $\left(X^{2}=286.42 ; d f=1 ; p<0.001\right)$. Similarly, respondents reported higher confidence when advising patients on LMWHs than DOACs $\left(X^{2}=41.49 ; d f=1 ; p<0.001\right)$. The distribution of respondents' confidence according to the various aspects of anticoagulation therapy is demonstrated in Fig. 1. It was clearly shown that respondents generally felt confident when discussing about indications $(n=499,92.1 \%)$ and benefits of anticoagulation therapy ( $n=483,89.1 \%)$ with patients. However, at least half of the respondents were not confident when it comes to INR monitoring and dosage adjustment $(n=271$, $50.0 \%)$, management of interactions $(n=258,47.6 \%)$ and management of bridging/switching from one anticoagulant to another ( $n=169,31.2 \%)$.

When respondents were asked on their perceived reason(s) which influencing their confidence level, most of the respondents reported that their experience in dealing with anticoagulation cases $(n=469,86.5 \%)$, knowledge on anticoagulants $(n=394,72.7 \%)$ and knowledge on the diseases requiring anticoagulation therapy $(n=311,57.4 \%)$ were the main reasons influencing their confidence level in providing pharmaceutical care to patients regarding anticoagulants. About $10 \%(n=59)$ of respondents claimed that the previous unfavourable experiences with anticoagulants affect their confidence level. When asked about the source of information used by respondents to obtain latest information regarding anticoagulants, more than half of the respondents utilised updated local/international guidelines $(n=366,67.5 \%)$, peer discussion $(n=333,61.4 \%)$ and medical websites $(n=283,52.2 \%)$. Non-medical website(s) $(n=53$, 6.5\%) was the least preferred choice of respondents for the obtainment of information. Up to $93.5 \%(n=507)$ respondents would like to receive additional education in the area of anticoagulation, particularly on the bridging/switching ( $n=460,90.7 \%)$, management of bleeding $(n=393,77.5 \%)$ and drug-drug, drug-food interaction $(n=390,76.9 \%)$. Besides that, few respondents commented that they were interested in the drug choice and dosing in special population.

\section{Socio-demographics associated with confidence level of respondents in providing necessary information to patient receiving warfarin, $\mathrm{LMWHs}$ and DOACs}

Figure 2 reports the socio-demographics that are associated with high confidence level in providing necessary information to patient receiving warfarin, LMWHs and DOACs using multiple logistic regression. Frequent user and ward pharmacists have been consistently found to be more confident in providing care on all anticoagulants compared to non-frequent user and non-ward pharmacists when adjusted for all variables. Apart from this, hospital pharmacists, compared to respondents who are working in clinics, has 1.6 times of odds (95\% CI 1.1; 2.5, $p<0.05)$ of being more confident in providing care on LMWHs. Those who had warfarin medication therapy adherence clinic (MTAC) exposure has 1.5 times of odds $(95 \% \mathrm{Cl} 1.1 ; 2.3)$ of greater confidence in dealing with DOACs compared to those who had never involved in warfarin MTAC previously.

\section{Discussion}

To the best of our knowledge, this is the first questionnaire survey ever conducted in Malaysia that assessed the confidence of pharmacists in dealing with anticoagulants. Overall, pharmacists working in Borneo have displayed a higher confidence level in providing necessary information to patient receiving warfarin compared to LMWHs and DOACs $(88.3 \%$ vs $58.5 \%$ vs $38.9 \%$, respectively). The findings were similar to a multinational survey conducted among pharmacist working in 18 countries [28], whereby the mean proportion of confidence with vitamin $\mathrm{K}$ antagonist and DOACs were reported as $78.2 \%$ (ranging from 54.5 to $97.0 \%$ among studied countries) and 53\% (ranging from 21.6 to $82.3 \%$ among the studied countries), respectively. In addition, Hamedi et al. [29] also reported that approximately $40 \%(n=102)$ of the community pharmacists in London felt uncertain or lacked of confidence in their knowledge on DOAC, compared to vitamin $\mathrm{K}$ antagonist $(n=59,23 \%)$. The higher confidence level reported by respondents in dealing with warfarin was not surprised as warfarin has been available for decades and is still widely use in the government healthcare facilities. Moreover, warfarin counseling is a part of module for pharmacist during pre-registration training that possibly lend them in attaining higher confidence in providing pharmaceutical care to patients receiving warfarin compared to other anticoagulants. 


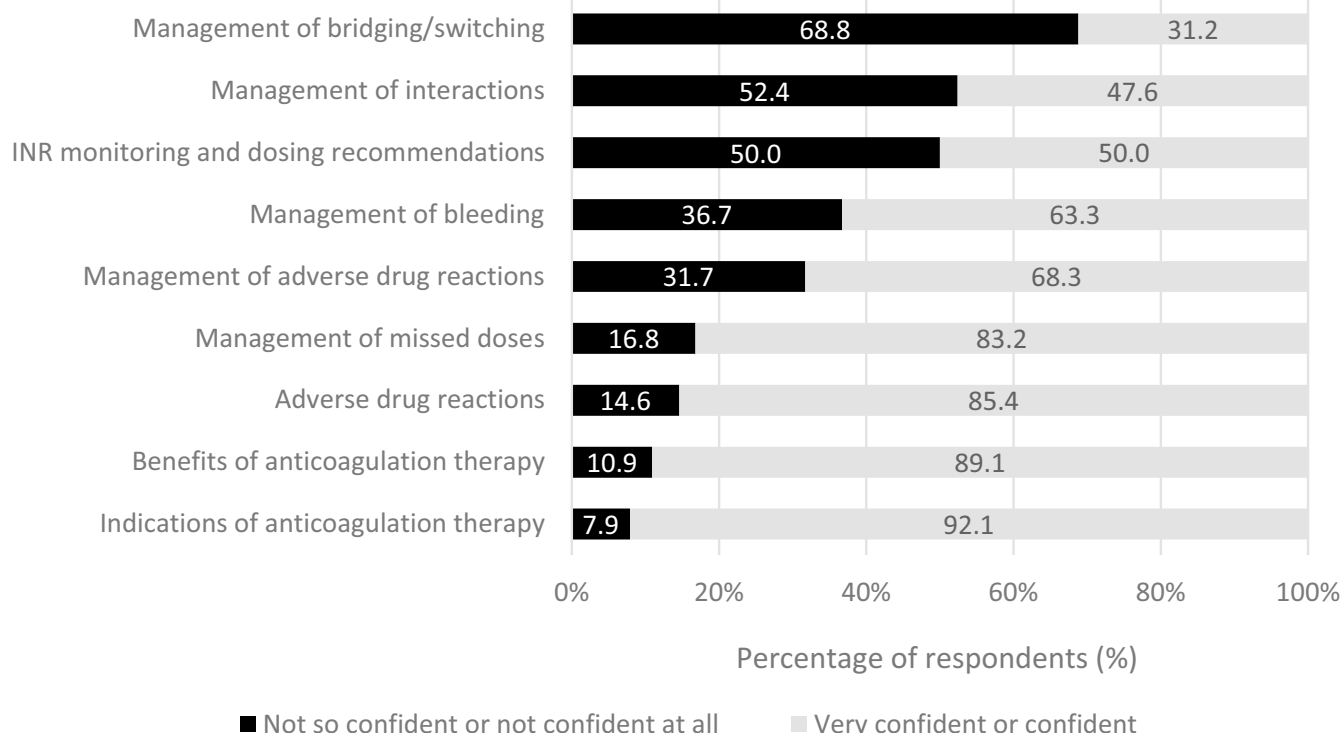

Fig. 1 Distribution of responses ( $n=542$ ) according to their confidence level in different aspects of anticoagulation therapy

Although DOACs demonstrated similar efficacy and a better safety profile compared to warfarin, medication adherence towards DOACs is very important as DOACs has relatively short half-lives and lack of routine therapeutic monitoring [25]. As pharmacists known as the most accessible health care providers, can play a role in management and monitoring of DOACs therapy [25]. However, the low confidence level in dealing with DOACs reported in this study is alarming as the usage of DOACs would be expected to increase in accordance to the latest guidelines' recommendation [7, 8] where DOACs are strongly recommended over warfarin in DOAC-eligible AF patients. Apart from that, Pharmaceutical Services Program, Ministry of Health Malaysia has recently published the Anticoagulation Medication Therapy Adherence Clinic (AC-MTAC) Protocol 2020 [24] and with the ongoing transition from Warfarin Medication Therapy Adherence Clinic (WMTAC) to ACMTAC, pharmacists will be expected to provide care to more DOACs patient in the future. Since more than half of the respondents agreed that knowledge about anticoagulants and knowledge on diseases requiring anticoagulation therapy were the factors affecting their confidence level, pharmacists should be proactive in enhancing their knowledge and skill towards management of anticoagulation (especially DOACs).

With regards to the confidence level of respondents in discussing various aspects of anticoagulation therapy with patients receiving anticoagulants, our results were consistent with the findings reported by Papastergious et al. [28], where more than half of the respondents claimed not so confident or not confident at all in management of bridging/switching from one anticoagulant to another, management of interactions as well as INR monitoring and dosing recommendations. Pharmacists generally doubt themselves in these areas as these are more complicated and require good clinical knowledge. Thus, these areas should be focused in future anticoagulation training workshop or education sessions. Local/international guidelines, peer discussion and reference to medical website(s) were the preferred way for pharmacists to obtain latest information on anticoagulation therapy. These results provided a general background on the preferred source of information by pharmacists and may aid in future planning in updating information about anticoagulants.

More than $95 \%$ of pharmacists express their interest in receiving additional education on different aspects in the area of anticoagulation therapy. Majority (over 90\%) were interested in receiving education on bridging/switching of anticoagulants, followed by $77.5 \%$ pharmacists who want to receive education in the management of bleeding associated with anticoagulants. The findings were in line with the published study where $68.2 \%$ of pharmacist wanted to receive education on bleeding management, whereas $66.0 \%$ were reportedly interested in getting additional education on management of switching [28]. This finding reflected the perceived need of education by pharmacist which they found difficult while advising patients on anticoagulants and could be used in developing relevant education programmes to fill gaps in their knowledge and boost their confidence. 


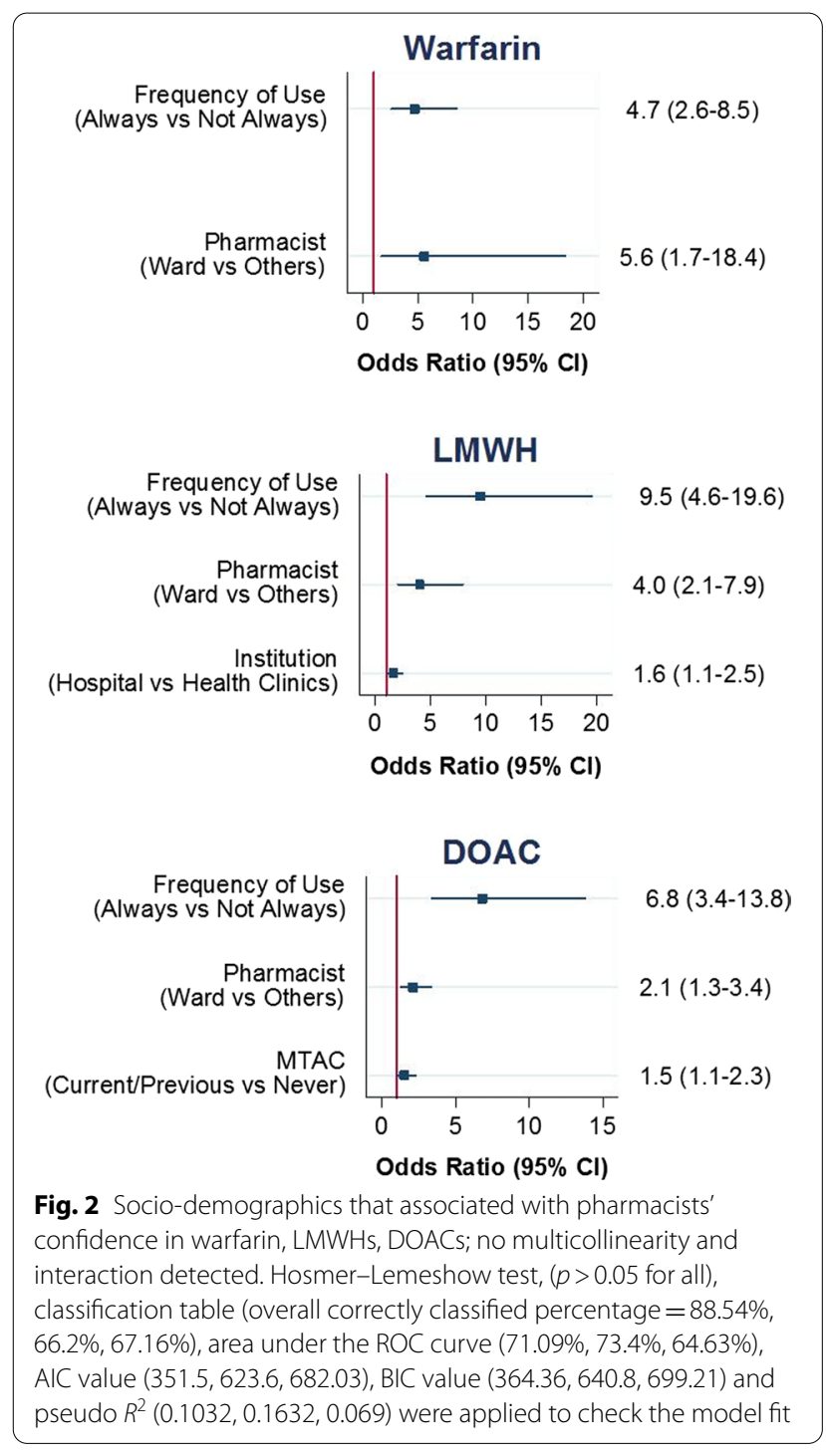

With regard to the evaluation of the socio-demographics associated with the pharmacists' confidence in providing pharmaceutical care on anticoagulation therapy, it was found that ward pharmacists and pharmacists who always encountered anticoagulants in their practice were consistently more confident in providing anticoagulantrelated pharmaceutical care. Ward pharmacists often deal with a variety of anticoagulation cases and involve in active communication with patients and their families; this leads them in acquiring better confidence level when providing care to patients. As for pharmacists who always deal with anticoagulants, they are likely to have more experience in dealing with the anticoagulants cases and this is being proven where majority of pharmacists $(n=223,85.8 \%)$ agreed that the experience in dealing with anticoagulant cases was the pivotal factor affecting their confidence level. Given the complexity of therapies and complications associated with VTE and AF, regardless of the type of anticoagulant used, the exposures to different case scenarios and regular training workshop or education sessions maybe required to enhance pharmacist's knowledge and confident. Pharmacist's prior or current medication therapy adherence clinic (MTAC) exposure contributed to a higher confidence level when dealing with DOACs. In Malaysia, pharmacists are required to undergo a 2-week warfarin MTAC training and pass examination before being recruited in warfarin MTAC services [33]. This sets a good foundation for pharmacists and with routine MTAC activities such as patient review and counselling, these are not only helpful in increasing patient adherence towards anticoagulants but may also substantially increase pharmacists' own knowledge and ultimately their confidence in the area of anticoagulation therapy [24, 34].

\section{Strength and limitation}

Strength of this study was the robust sampling that was able to have sufficient representation from all levels of practising pharmacists such as urban and suburban, hospital and clinics as well as various levels of pharmacist position in government setting. These enable us to generalise the findings among government pharmacists working in Borneo (both Sabah and Sarawak). Even though the findings may not be representative of the confidence level of pharmacist in the area of anticoagulation working in the other states of Malaysia, this study could provide a basis for conducting a large-scale national survey for the generalisation of the results. This study was crosssectional in nature, thus unable to identify changes in the confidence level of pharmacists over time in the long run. As responses were reported from pharmacist working in the government settings only, confidence level of pharmacist working in private sectors, retail or in community pharmacies remains unknown and should be evaluated by future studies.

\section{Conclusion}

This study assessed the confidence level in providing pharmaceutical care on commonly used anticoagulants, namely warfarin, LMWHs and DOACs in Borneo, Malaysia. Results of this study suggested that Borneo pharmacists has higher confidence level in providing pharmaceutical care to patients receiving warfarin compared to low molecular weight heparins and direct oral anticoagulants. Keeping abreast with current guidelines through structured and continuous educational programme is urgently needed to ensure the safety and efficacy of anticoagulation therapy. 


\section{Supplementary Information}

The online version contains supplementary material available at https://doi. org/10.1186/s40545-021-00377-w.

Additional file 1. Supplementary appendix for sample size calculation, questionnaire and its' original psychometric properties.

\section{Acknowledgements}

We would like to thank all the respondents for their time answering the questionnaire survey.

\section{Authors' contributions}

All authors contributed in all parts for the study. All authors reviewed and approved the final manuscript.

\section{Funding}

This research did not receive any specific grant from any sector.

\section{Availability of data and materials}

The datasets used and/or analysed during the current study are available from the corresponding author on reasonable request.

\section{Declarations}

\section{Ethics approval and consent to participate}

This study was approved by the Medical Research and Ethics Committee, Malaysia with the identification code of NMRR-18-2821-44278 (IIR) for Sabah and NMRR-19-3270-51648 for Sarawak. All respondents gave their consent for answering the questionnaire.

\section{Consent for publication}

Not applicable.

\section{Competing interests}

The authors declare no conflict of interest.

\section{Author details}

'Pharmacy Department, Hospital Queen Elizabeth II, Kota Kinabalu, Sabah, Malaysia. ${ }^{2}$ Pharmacy Department, Sarawak General Hospital, Kuching, Sarawak, Malaysia. ${ }^{3}$ Pharmacy Department, Queen Elizabeth Hospital, Kota Kinabalu, Sabah, Malaysia. ${ }^{4}$ School of Pharmaceutical Sciences, Universiti Sains Malaysia, Penang, Malaysia.

Received: 5 February 2021 Accepted: 30 October 2021

Published online: 09 November 2021

\section{References}

1. Alquwaizani M, Buckley L, Adams C, Fanikos J. Anticoagulants: a review of the pharmacology, dosing, and complications. Curr Emerg Hosp Med Rep. 2013. https://doi.org/10.1007/s40138-013-0014-6.

2. Barnes GD, Lucas E, Alexander GC, Goldberger ZD. National trends in ambulatory oral anticoagulant use. Am J Med. 2015. https://doi.org/10. 1016/j.amjmed.2015.05.044.

3. Roderick P. Epidemiology of venous thromboembolism. Clin Risk. 1997. https://doi.org/10.1177/135626229700300301

4. Lee LH, Gallus A, Jindal R, Wang C, Wu CC. Incidence of venous thromboembolism in Asian populations: a systematic review. Thromb Haemost. 2017. https://doi.org/10.1160/TH17-02-0134.

5. Lim CW, Kasim S, Ismail JR, Yul N, Chua C, Khir RN, et al. Prevalence of atrial fibrillation in the Malaysian communities. Heart Asia. 2016. https://doi. org/10.1136/heartasia-2016-010775.

6. Lip GYH, Nieuwlaat R, Pisters R, Lane DA, Crijns HJGM, Andresen D, et al. Refining clinical risk stratification for predicting stroke and thromboembolism in atrial fibrillation using a novel risk factor-based approach: the
Euro Heart Survey on atrial fibrillation. Chest. 2010. https://doi.org/10. 1378/chest.09-1584.

7. January CT, Wann LS, Calkins H, Chen LY, Cigarroa JE, Cleveland JC, et al. AHA/ACC/HRS FOCUSED UPDATE of the 2014 AHA/ACC/HRS Guideline for the Management of Patients With Atrial Fibrillation: A Report of the American College of Cardiology/American Heart Association Task Force on Clinical Practice Guidelines and the Heart R. Circulation. 2019. https:// doi.org/10.1161/CIR.0000000000000665.

8. Hindricks G, Potpara T, Dagres N, Arbelo E, Bax JJ, Blomström-Lundqvist C, et al. ESC Guidelines for the diagnosis and management of atrial fibrillation developed in collaboration with the European Association of Cardio-Thoracic Surgery (EACTS). Eur Heart J. 2020. https://doi.org/10. 1093/eurheartj/ehaa612.

9. Mazzolai L, Aboyans V, Ageno W, Agnelli G, Alatri A, Bauersachs R, et al. Diagnosis and management of acute deep vein thrombosis: a joint consensus document from the European Society of Cardiology working groups of aorta and peripheral vascular diseases and pulmonary circulation and right ventricular function. Eur Heart J. 2018. https://doi.org/10. 1093/eurheartj/ehx003.

10. Schünemann HJ, Cushman M, Burnett AE, Kahn SR, Beyer-Westendorf J, Spencer FA, et al. American Society of Hematology 2018 guidelines for management of venous thromboembolism: prophylaxis for hospitalized and nonhospitalized medical patients. Blood Adv. 2018. https://doi.org/ 10.1182/bloodadvances.2018022954.

11. Kearon C, Elie A, Akl JO, Blaivas A, Jimenez D, Bounameaux H, Huisman $M$, et al. Antithrombotic therapy for VTE disease: CHEST Guideline. Chest. 2016. https://doi.org/10.1016/j.chest.2015.11.026.

12. Ministry of health of Malaysia. Clinical practice guideline venous thromboembolism prevention and treatment of. vol. 13. 2017.

13. Aziz ZA, Sidek NN, Kamarudin MK, Baharum N, Muneer A, Hamid A, et al Annual report of the Malaysian Stroke Registry. 2016.

14. Hart RG, Pearce LA, Aguilar MI. Meta-analysis: antithrombotic therapy to prevent stroke in patients who have nonvalvular atrial fibrillation. Ann Intern Med. 2007. https://doi.org/10.7326/0003-4819-146-12-20070 6190-00007.

15. Kirchhof P, Uk C, Uk DK, Uk BC, Germany HD, Heidbuchel H, et al. ESC Guidelines for the management of atrial fibrillation developed in collaboration with EACTS The Task Force for the management of atrial fibrillation of the European Society of Cardiology (ESC) Developed with the special contribution of the Europe. Eur Heart J. 2016. https://doi.org/10.1093/ eurheartj/ehw210.

16. Mismetti P, Schellong S, Eriksson H, Baanstra D, Sc M, Schnee J, et al. Dabigatran versus warfarin in the treatment of acute venous thromboembolism. N Engl J Med. 2009. https://doi.org/10.1056/NEJMoa0906598.

17. Hacke W, Ph D, Breithardt G, Halperin JL, Hankey GJ, Piccini JP, et al. Rivaroxiban versus warfarin in nonvalvular atrial fibrillation. N Engl J Med. 2011. https://doi.org/10.1056/NEJMoa1009638.

18. Hylek EM, Hanna M, Al-khalidi HR, Ph D, Ansell J, Atar D, et al. Apixaban versus warfarin in patients with atrial fibrillation. N Engl J Med. 2011. https://doi.org/10.1056/NEJMoa1107039.

19. Gallus AS, Johnson M, Masiukiewicz U, Pak R, Ph D, Thompson J, et al. Oral apixaban for the treatment of acute venous thromboembolism. N Engl J Med. 2013. https://doi.org/10.1056/NEJMoa1302507.

20. Investigators TH. Edoxaban versus warfarin for the treatment of symptomatic venous thromboembolism. N Engl J Med. 2013. https://doi.org/10. 1056/NEJMoa1306638

21. Eikelboom J, Oldgren J, Ph D, Parekh A, Pogue J, Sc M, et al. Dabigatran versus warfarin in patients with atrial fibrillation. N Engl J Med. 2009. https://doi.org/10.1056/NEJMoa0905561.

22. Scott D, Brenner B, Buller HR, Gallus AS, Anthonie W, Misselwitz F, et al. Oral rivaroxaban for symptomatic venous thromboembolism. N Engl J Med. 2010. https://doi.org/10.1056/NEJMoa1007903.

23. Pharmaceutical Services Programme Ministry of Health Malaysia. Malaysian Statistics on Medicines. 2016.

24. Ministry of health of Malaysia. Anticoagulation MTAC (AC-MTAC) protocol 2nd edition (2020). vol. 2. 2020.

25. Leblanc K, Semchuk WM. A pharmacist checklist for direct oral anticoagulant management: raising the bar. Can Pharm J. 2018. https://doi.org/10. $1177 / 1715163518756926$. 
26. Ashjian E, Pharm D, Kurtz B, Pharm D, Renner E, Pharm D, et al. Evaluation of a pharmacist-led outpatient direct oral anticoagulant service. Am J Health Pharm. 2017. https://doi.org/10.2146/ajhp151026.

27. Manzoor BS, Cheng W, Lee JC, Uppuluri EM, Edith A. Quality of pharmacist-managed anticoagulation therapy in long-term ambulatory settings: a systematic review. Ann Pharmacother. 2017. https://doi.org/10.1177/ 1060028017721241

28. Papastergiou J, Kheir N, Ladova K, Rydant S. Pharmacists' confidence when providing pharmaceutical care on anticoagulants, a multinational survey. Int J Clin Pharm. 2017. https://doi.org/10.1007/ s11096-017-0551-2.

29. Hamedi N, da Costa FA, Horne R, Levitan M, Begley A, Antoniou S. How prepared are pharmacists to support atrial fibrillation patients in adhering to newly prescribed oral anticoagulants? Int J Clin Pharm. 2017. https:// doi.org/10.1007/s11096-017-0529-0.

30. Ministry of health of Malaysia. Ministry of Health. Ministry of Health Medicines Formulary (MOHMF) 2018:1-346. https://www.pharmacy.gov. my/v2/sites/default/files/document-upload/fukkm-1-2020_0.pdf.
31. Naing L, Winn T, Rusli BN. Practical issues in calculating the sample size for prevalence studies. Arch Orofac Sci. 2006;1:9-14.

32. Lindsey C, Sheather S. GVSELECT: Stata module to perform best subsets variable selection, Statistical Software Components S457816. Boston College Department of Economics. 2014.

33. Ministry of Health Malaysia. Record of Training and Experience of provisionally registered pharmacist (PRP) - Community Pharmacy. 2017.

34. Nutescu EA, Shapiro NL, Ibrahim S, West P. Warfarin and its interactions with foods, herbs and other dietary supplements. Expert Opin Drug Saf. 2006. https://doi.org/10.1517/14740338.5.3.433.

\section{Publisher's Note}

Springer Nature remains neutral with regard to jurisdictional claims in published maps and institutional affiliations.
Ready to submit your research? Choose BMC and benefit from:

- fast, convenient online submission

- thorough peer review by experienced researchers in your field

- rapid publication on acceptance

- support for research data, including large and complex data types

- gold Open Access which fosters wider collaboration and increased citations

- maximum visibility for your research: over 100M website views per year

At BMC, research is always in progress.

Learn more biomedcentral.com/submissions 